\title{
放牧对内蒙古锡林河流域草原土壤碳组分的影响
}

\author{
马秀枝 ${ }^{1}$ 王艳芬 $^{2 *}$ 汪诗平 ${ }^{1}$ 王金枝 ${ }^{1} \quad$ 李长生 $^{3}$
}

（1 中国科学院植物研究所, 北京 100093）（2 中国科学院研究生院, 北京 100039）

（3中国农业科学院农业资源与农业区划研究所, 北京 100081)

摘 要 选择内蒙古锡林河流域三种草原, 较系统地研究了放牧对微生物量碳 (MB-C) 和易分解碳 ( Lab-C ) 两种碳 素组分的影响。结果表明, 自由放牧 22 年后, 羊草 (Leymus chinensis) 草原土壤 $0 \sim 10 \mathrm{~cm}$ 和 10 20 cm 土层土壤微生 物量碳分别下降了 $27.9 \%$ 和 $12.8 \%$; 土壤易分解碳分别下降了 $22.0 \%$ 和 $12.6 \%$, 自由放牧没有改变羊草草原土壤 活性碳的季节变化形式。大针茅 (Stipa grandis) 草原 $0 \sim 5 \mathrm{~cm}$ 表层和 $5 \sim 15 \mathrm{~cm}$ 下层土壤微生物量碳分别下降了 $38.2 \%$ 和 $12.2 \%$ 。大针茅草原季节波动出现高峰的时间较羊草草原推后, 基本在 8 月下旬, 并且与地上生物量存在 明显的正相关关系 $(p<0.001)$ 。土壤活性碳在表征羊草草原和大针茅草原土壤的动态变化时, 要敏感于土壤总有 机碳。冷蒿-小禾草草原 (Artemisia frigida-short bunchgrasses steppe)连续放牧 11 年恢复 2 年后, 土壤各碳素组分都没 有发生明显变化, 但随着放牧率的增加, MB-C/Org-C 比值和 Lab-C/Org-C 比值逐渐降低, 表现为轻牧 > 中牧 > 重牧, 这说明, 在表征放牧对冷蒿-小禾草草原土壤的影响指示上, MB-C/Org-C 和 Lab-C/Org-C 要比 MB-C 和 Lab-C 敏感。

关键词 放牧 微生物量碳 易分解碳 碳组分 内蒙古草原

\section{IMPACTS OF GRAZING ON SOIL CARBON FRACTIONS IN THE GRASSLANDS OF XILIN RIVER BASIN, INNER MONGOLIA}

\author{
MA Xiu-Zhi ${ }^{1}$ WANG Yan-Fen ${ }^{2}$ WANG Shi-Ping ${ }^{1}$ WANG Jin-Zhi ${ }^{1}$ and LI Chang-Sheng ${ }^{3}$ \\ (1 Institute of Botany, Chinese Academy of Sciences, Beijing 100093, China) \\ (2 Graduate School of Chinese Academy of Sciences, Beijing 100039, China) \\ (3 Institute of Agricultural Resources and Regional Planning, Chinese Academy of Agricultural Sciences, Beijing 100081, China)
}

\begin{abstract}
Inner Mongolia grasslands are an important ecosystem of the Euro-Asia plateau. However, in recent decades, it has been severely degraded due to overgrazing, and, at the same time, soil carbon storage has changed. Because of the high background variation and diversity of natural soils, it is difficult to detect changes in soil carbon pools, especially over short time periods. Some experiments have attempted to detect changes in different fractions of soil carbon pools. In Inner Mongolia grasslands, experiments have showed there was no evident decrease of soil organic carbon for grazing. In this study, we examined the effects of grazing on soil carbon fractions: soil microbial carbon (MB-C) and soil labile carbon ( Lab-C) in the grasslands of the Xilin River Basin of Inner Mongolia. MB-C was determined using the chloroform fumigation method and Lab-C was determined using the potassium permanganate oxidation method. The results indicated that after 22 years of grazing in Leymus chinensis dominated grasslands. Soil microbial biomass decreased by $27.9 \%$ and $12.8 \%$ in the $0-10 \mathrm{~cm}$ and $10-20 \mathrm{~cm}$ layers, respectively, and Lab-C decreased by $22.0 \%$ and $12.6 \%$ in the two soil layers. After 22 years of grazing in a Stipa grandis grassland, MB-C decreased by $38.2 \%$ and $12.2 \%$ in the $0-5 \mathrm{~cm}$ and $5-15 \mathrm{~cm}$ soil layers, respectively. The time at which soil microbial biomass reached a peak in $S$. grandis was delayed (August) as compared to L. chinensis, and MB-C was significantly correlated with aboveground grass biomass $(p<0.0001)$. Soil microbial carbon and Lab-C were more sensitive than SOC to the impacts of grazing on changes in soil carbon storage. There were no significant decreases in any of the soil carbon fractions in the Artemisia frigida + short bunchgrasses grassland with increases in the stocking rates, but the ratios of MB-C/total $\mathrm{C}$ and Lab-C/total $\mathrm{C}$ decreased gradually with increases in stocking rates. These results indicate that the ratios of $\mathrm{MB}-\mathrm{C} /$ total $\mathrm{C}$ and $\mathrm{Lab}-\mathrm{C} /$ total $\mathrm{C}$ are more sensitive indicators than MB-C and Lab-C in reflecting soil carbon changes under grazing pressure in the Artemisia frigida + short bunchgrasses grassland.
\end{abstract}

Key words Grazing, Soil carbon fractions, Inner Mongolia Grasslands 
自工业革命以来, 人类活动对生物圈的影响已 由区域扩展到全球, 特别是大气中 $\mathrm{CO}_{2}$ 和 $\mathrm{CH}_{4}$ 等温 室气体浓度在逐年增加。到 2010 年 $\mathrm{CO}_{2}$ 浓度将达 到 $540 \sim 970 \mu \mathrm{g} \cdot \mathrm{g}^{-1}$, 而在工业化前和 2000 年却分别 为 $280 \mu \mathrm{g}^{\bullet} \mathrm{g}^{-1}$ 和 $360 \mu \mathrm{g}^{\bullet} \mathrm{g}^{-1}$ ( IPCC, 2001)。长期非持 续性土地利用导致碳素从陆地生态系统中的释放是 大气中 $\mathrm{CO}_{2}$ 浓度不断升高的一个主要原因 (Sampson et al , , 1993), 精确估计土地利用变化对陆地生态系 统碳平衡的影响是当前全球变化和全球碳循环研究 的重要内容 (Watson \& Verardo, 2000; Kelling, 1997)。

草原是世界陆地生态系统的重要类型, 约占陆 地生态系统总面积的 $46 \%$, 其碳素储量约占陆地生 态系统碳素总储量的 15.2\% (Houghton, 1995)。开垦 和过度放牧被认为是导致草原非持续性利用和土壤 碳素损失的主要途径 (Graetz, 1994)。

内蒙古草原是欧亚大陆草原的重要组成部分, 也是温带地区保存较好的天然草原之一, 放牧是其 主要的土地利用方式。随着人口压力的不断增大, 不合理的放牧不仅恶化了草原地区的生态环境, 而 且对草原温室气体的收支产生影响, 最终造成土壤 有机碳储量的下降 (李凌浩, 1998)。王艳芬等 (1998) 发现, 内蒙古冷蒿-小禾草草原( Artemisia frigi$d a$-short bunchgrasses steppe) 重度放牧条件下每年比 轻牧多损失 $161.37 \mathrm{~g} \mathrm{C} \cdot \mathrm{m}^{-2}$, 而重牧条件下碳的输 入与轻牧相比并未增加, 所以多损失的碳有可能来 自土壤有机碳。

有关放牧对草地土壤有机碳的影响国内外研究 得很多, 但因研究方法以及草地类型和管理方式的 不同, 目前学术界对放牧影响土壤有机碳含量和储 量的认识还存在分歧。澳大利亚东北部的两个半干 旱草原的研究结果表明, 重度放牧 6 8 年后土壤有 机碳的总储量没有显著变化 (Holt, 1997)。其它地区 也发现类似的结果 (Milchunas \& Laurenroth, 1993); 然 而, 也有实验结果表明放牧提高了土壤有机碳水平 (Schuman et al., 1999; Weinhold et al.,2001); 有的结 果却发现放牧降低了土壤有机碳水平 (Frank et al.,

1995; Derner et al ., 1997; Bauer et al., 1987)。

上述实验多为定性的比较实验, 多集中于放牧 对总有机碳影响的研究。但实际上, 由于自然土壤 的高背景值和土壤类型的多样性, 土壤总碳的微小 变化对外界的反应总是难以观测到, 尤其是在较短 的时间尺度上, 土壤总碳库对人类活动的影响并不 显著, 所以有人建议用土壤有机碳亚库, 即碳素组分 来表征土壤碳对人类活动的响应 (Blair \& Lefroy,
1995)。

Blair 和 Lefroy (1995) 根据碳素周转速率将土壤 中的有机碳分为 5 个碳库, 即有效碳 (Available carbon)、水溶性有机碳 (Water-soluble organic carbon, WSOC)、易分解碳 (Labile carbon)、可矿化碳 (Miner liable carbon)、微生物量碳( Microbial carbon), 他认为 土壤碳库的变化主要发生在易分解碳库里。Biederbeck 和 Zentner (1994) 也认为, 土壤有机质的短暂波 动主要发生在易分解部分, 并选择易分解碳、可矿化 碳及微生物量碳作为土壤有机碳变化的指示因子。 Wolters 和 Joergensen( 1993) 认为土壤微生物量碳/全 碳的比值可以作为土壤碳库质量的敏感因子, 土壤 可矿化碳/全碳的比值可以用来表示土壤有机碳的 活性。由于土壤活性有机碳对外界环境的变化较总 有机碳更敏感, 可以反映土壤全碳的微小变化, 又 直接参与土壤生物化学转化过程, 因而可作为评价 土壤碳平衡及肥力状况的重要指标 (徐阳春和沈其 荣,2001)。

在内蒙古草原, 放牧强度在短时期内对典型草 原植被下的栗钙土有机碳含量没有显著影响(王艳 芬等, 1998); 内蒙古羊草草原和大针茅草原, 轻度放 牧也没有明显降低土壤有机碳含量 ( Cui et al., 2005)。重度放牧 6 8 年后土壤有机碳的总储量没 有显著变化, 但是土壤微生物量碳分别下降了 $51 \%$ 和 24\% (Holt, 1997)。

本文选择内蒙古典型草原羊草草原和大针茅草 原 (自由放牧 22 年) 以及处于退化演替恢复阶段的 冷蒿-小禾草草原 (实验连续放牧 11 年恢复 2 年), 研究放牧对土壤微生物量碳和易分解碳的影响及它 们的季节动态, 以期找出其中对放牧的敏感因子, 为 及早预测放牧对土壤造成的影响、实现草地资源的 可持续利用和有效管理提供理论依据。

\section{1 研究地区概况}

研究区域位于内蒙古高原东部的锡林郭勒草 原, 草地为典型的温带草原, 在中国温带草原及整 个欧亚大陆草原区域均具明显代表性。本区域属于 温带半干旱气候, 年平均气温约 $1{ }^{\circ} \mathrm{C}$, 最低气温 (1 月)为 $-17{ }^{\circ} \mathrm{C}$, 最高气温 ( 7 月)为 $18{ }^{\circ} \mathrm{C}$, 年平均降水 量为 $350 \mathrm{~mm}$, 且降水集中在 $6 \sim 8$ 月 (占年降水的 $60 \% \sim 80 \%$ )。

本实验选择在“中国科学院草原生态系统定位

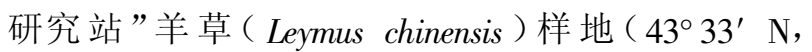
$116^{\circ} 37^{\prime}$ E) 和大针茅 ( Stipa grandis) 样地 $\left(43^{\circ} 44^{\prime} \mathrm{N}\right.$, 
$116^{\circ} 32^{\prime}$ E) 进行, 样地自 1980 年起进行围栏封育实 验, 栏外一直处于自由放牧状态。本实验选择距栏 外约 $100 \mathrm{~m}$ 生境相同的自由放牧区作为对照; 另一

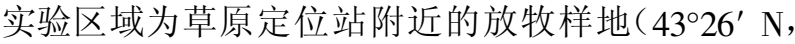
$\left.116^{\circ} 37^{\prime} \mathrm{E}\right), 1989$ 年围封, 共设 1.33 、4 和 6.67 只羊・ $\mathrm{hm}^{-2} 3$ 种放牧率, 分别代表轻、中、重牧。1990 1998 年用羯羊进行轮牧实验, 2000 以后该实验停止 放牧, 为放牧演替恢复阶段。各放牧率的小区采用 不完全拉丁方设计, 尽量消除小区间的差异。

\section{2 样品采集及分析}

于 2002 年 5 10 月整个生长季内, 各样地中选 择地势平坦、植被有代表性的地段, 按 $\mathrm{S}$ 型走向, 相 隔约 $30 \mathrm{~m}, 5$ 次重复, 羊草样地和放牧样地按 $0 \sim 10$ $\mathrm{cm}$ 和 $10 \sim 20 \mathrm{~cm}$ 层位取样, 大针茅样地按 $0 \sim 5 \mathrm{~cm}$ 和 $5 \sim 15 \mathrm{~cm}$ 层位取样, 每次重复为 $1 \mathrm{~m} \times 1 \mathrm{~m}$ 的样方 内按 5 点法取样混合而成。新鲜土样回到室内捡掉 植物残体, 迅速过 $2 \mathrm{~mm}$ 篎, 混匀后分成两部分, 一 部分置于 $4{ }^{\circ} \mathrm{C}$ 冰箱中保存, 以供培养微生物使用, 测 定土壤微生物量碳, 另一部分置于室温下风干, 用以 测定土壤易氧化碳(针茅样地只测了土壤微生物量 碳)。分别于生长期内 ( $5 \sim 10$ 月) 取样 4 次, 每次取 样间隔约 $30 \sim 45 \mathrm{~d}$ 。

土壤样品的分析方法:

1)土壤微生物量碳: 氯仿熏蒸浸提法 (Jenkinson \& Powlson，1976; 林启美和吴玉光，1999）。

微生物量碳 $C_{\mathrm{mic}}=F_{\mathrm{s}} / 0.45, F_{\mathrm{s}}$ 为熏蒸与不熏 蒸土壤中有机碳的差值, 微生物量碳的单位是 $\mathrm{mg} \cdot \mathrm{kg}^{-1}$ 。

2) 土壤易分解碳: 高锰酸钾氧化法 (Blair \& Lefroy，1995)用 $333 \mathrm{mmol} \cdot \mathrm{L}^{-1}$ 的 $\mathrm{KMnO4}$ 氧化, 根据 消耗的 $\mathrm{KMnO}_{4}$ 溶液的量 $\left(1 \mathrm{mmol} \mathrm{KMnO}_{4}\right.$ 溶液氧化
$1 \mathrm{mg}$ 的碳), 求出样品中易氧化碳含量, 单位是 $\mathrm{g} \bullet \mathrm{kg}^{-1}$ 。

\section{3 统计分析}

应用软件 $\operatorname{SPSS}($ ver. 10.0) 的 ANOVA 方法以及 General Linear Model 下的 Univariate 单因素多变量进 行显著性分析。

\section{4 结 果}

\section{1 放牧对微生物量碳 $\left(C_{\mathrm{mic}}\right)$ 的影响}

土壤微生物是土壤中物质循环的调节者, 同时 也是有机物质库和速效养分的一部分, 是对环境变 化最敏感的因素 (Jenkinson, 1988)。微生物量碳约占 土壤全碳的 $0.5 \% \sim 4.6 \%$, 是土壤活性的植物营养 库, 与土壤有机碳极相关 (Marumoto \& Domsch, 1982)。从 $C_{\mathrm{mic}}$ 的平均值来看, 围封后的大针茅草原 $>$ 羊草草原 > 冷蒿-小禾草草原, 但放牧条件下冷蒿 一小禾草草原的 $C_{\text {mic }}$ 反而大于羊草和针茅草原。土 壤微生物量碳随深度的增加而下降, 放牧降低了下 降的幅度, 因为放牧降低了表层土壤的微生物量碳 含量, 其中放牧条件下下降的幅度针茅草原要大于 羊草和小禾草草原 (表 1 )。

\section{1 .1 羊草草原微生物量碳}

围封后羊草草原表层土壤微生物量碳平均为 $390.4 \mathrm{mg} \cdot \mathrm{kg}^{-1}$, 放牧条件下微生物量碳为 281.4 $\mathrm{mg} \cdot \mathrm{kg}^{-1}$ 。与围封相比, 自由放牧降低了土壤微生物 量碳, 其中表层和下层土壤分别下降了 $27.9 \%$ 和 $12.8 \%$ (表 1)。微生物量碳表现出明显的季节变化 规律, 表层和下层的季节变化都呈单峰曲线, 在 6 8 月植物生长旺期达到高峰, 之后随生长季的结束 又逐渐下降。

Mazzarin 和 Szott(1993)认为, 微生物量的季节变

表 1 不同类型草原土壤微生物量碳含量 $\left(\mathbf{m g} \cdot \mathbf{k g}^{-\mathbf{1}}\right)$ 及其剖面分布

Table 1 Impacts of grazing on soil microbial carbon and its vertical distribution

\begin{tabular}{|c|c|c|c|c|c|c|c|}
\hline \multirow{2}{*}{$\begin{array}{l}\text { 土层 } \\
\text { Soil layer }\end{array}$} & \multicolumn{2}{|c|}{$\begin{array}{c}\text { 羊草草原 } \\
\text { Leymus chinensis grassaland }\end{array}$} & \multicolumn{2}{|c|}{$\begin{array}{c}\text { 大针茅草原 } \\
\text { Stipa grandis grassland }\end{array}$} & \multicolumn{3}{|c|}{$\begin{array}{c}\text { 冷蒿-小禾草草原 } \\
\text { Artemisia frigida-short bunchgrass steppe }\end{array}$} \\
\hline & $\begin{array}{c}\text { 围封 } \\
\text { Enclosure }\end{array}$ & $\begin{array}{c}\text { 自由放牧 } \\
\text { Grazing }\end{array}$ & $\begin{array}{c}\text { 围封 } \\
\text { Enclosure }\end{array}$ & $\begin{array}{c}\text { 自由放牧 } \\
\text { Grazing }\end{array}$ & $\begin{array}{l}\text { 轻牧 } \\
\text { LG }\end{array}$ & $\begin{array}{l}\text { 中牧 } \\
\text { MG }\end{array}$ & $\begin{array}{c}\text { 重牧 } \\
\mathrm{HG}\end{array}$ \\
\hline 表层 Top layer $\left(\mathrm{g}^{\bullet} \mathrm{kg}^{-1}\right)$ & $390.4 \pm 59.9$ & $281.4 \pm 54.6$ & $496.2 \pm 70.7$ & $306.5 \pm 54.2$ & $356.3 \pm 30.4$ & $347.7 \pm 18.7$ & $355.4 \pm 34.9$ \\
\hline 下层 Sub layer $\left(\mathrm{g}^{\bullet} \mathrm{kg}^{-1}\right)$ & $230.9 \pm 37.4$ & $201.3 \pm 40.4$ & $321.9 \pm 64.8$ & $282.7 \pm 13.8$ & $209.4 \pm 28.4$ & $161.5 \pm 21.5$ & $191.1 \pm 26.8$ \\
\hline$(\mathrm{T}-\mathrm{S}) / \mathrm{T}(\%)$ & 0.8 & 28.4 & 35.1 & 7.8 & 41.2 & 53.5 & 46.2 \\
\hline
\end{tabular}

1) LG: 轻牧 Light grazing (1.33 只羊 $\left.\bullet \mathrm{hm}^{-2}\right) \quad \mathrm{MG}$ : 中牧 Middle grazing (4只羊 $\left.\bullet \mathrm{hm}^{-2}\right) \quad \mathrm{HG}$ : 重牧 Heave grazing $\left(6.67\right.$ 只羊・ hm $\left.{ }^{-2}\right)$

2) 羊草样地和放牧样地表层为 $0 \sim 10 \mathrm{~cm}$, 下层为 $10 \sim 20 \mathrm{~cm}$; 大针茅样地表层为 $0 \sim 5 \mathrm{~cm}$, 下层为 $5 \sim 15 \mathrm{~cm}$ Top layer is $0-10 \mathrm{~cm}$ in Leymus chinensis grassland and Artemisia frigida-short bunchgrass steppe, $0-5 \mathrm{~cm}$ in Stipa grandis grassland; Sub layer is $10-20 \mathrm{~cm}$ in Leymus chinensis grassland and Artemisia frigida-short bunchgrass steppe, $5-15 \mathrm{~cm}$ in Stipa grandis grassland

$3)(\mathrm{T}-\mathrm{S}) / \mathrm{T}(\%)$ 为沿土层下降的土壤微生物量碳占表层土壤微生物量碳的百分比 $(\mathrm{T}-\mathrm{S}) / \mathrm{T}(\%)$ is the decrease percent of soil microbial biomass along soil layer to the soil microbial biomass in top soil 


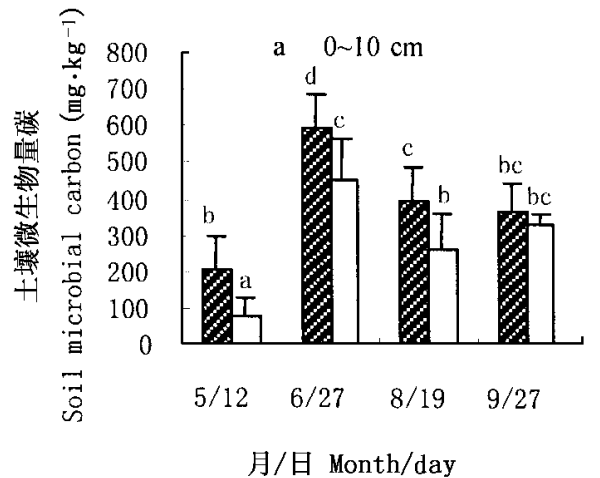

放牧 Grazing

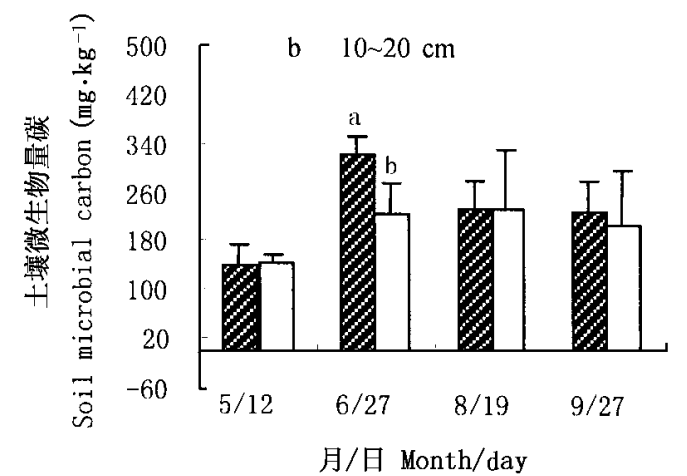

无牧 No grazing

图 1 自由放牧对羊草草原土壤微生物量碳的影响

Fig. 1 Impacts of grazing on soil microbial carbon in the Leymus chinensis grassland of Xilin River basin 字母不同者为差异显著 Significant difference with different letters $(p<0.05)$

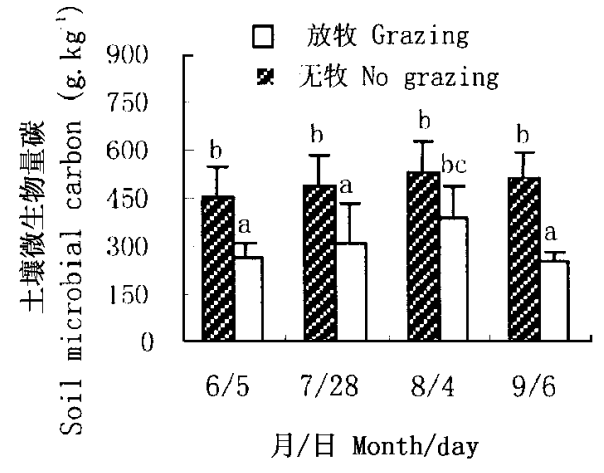

图 2 自由放牧对大针茅草原 $0 \sim 5 \mathrm{~cm}$ 土壤微生物量碳的影响 Fig.2 Impacts of grazing on soil microbial biomass in the Stipa grandis grassland of Xilin River basin

字母不同者为差异显著 Significant difference with different letters $(p<0.05)$

化与植物物候学、管理制度以及土壤湿度有关。土 壤湿度显著影响土壤微生物量的大小 ( Sparling \& West, 1989)。本实验中土壤微生物量与土壤湿度呈 明显的正相关 $(p<0.05, n=5), 7 \sim 8$ 月正是内蒙古 草原的雨季, 水分条件相对较好。

对羊草草原的放牧与否、季节、土壤深度 3 因素 方差分析表明, 季节以及季节与土壤深度的交互效 应对微生物量碳都有显著影响 $(p<0.05)$ 。放牧使 表层土壤微生物碳在各个时期均有下降, 除 9 月 27 日外, 其它取样时间两种处理之间均达到了显著水 平 $(p<0.01)$ (图 1), 这说明围封后, 随着植物立枯 和调落物量的增加, 地表的植物残体进入土壤, 为微 生物的生长和繁殖提供了必要的条件, 也必然加速
了有机物质的矿化和腐殖化过程, 微生物碳的含量 也得到了提高。而下层土壤只有在 6 月 27 日有显 著提高。这是因为 $10 \sim 20 \mathrm{~cm}$ 土层本身微生物碳含 量低于 $0 \sim 10 \mathrm{~cm}$, 而且受地表植被状况影响较小, 所 以围封后对其影响要小于表层土壤。

\subsection{2 针茅草原微生物量碳}

围封后针茅草原表层土壤微生物量碳为 496.2 $\mathrm{mg} \bullet \mathrm{kg}^{-1}$; 放牧条件下微生物量碳为 $306.5 \mathrm{mg} \cdot \mathrm{kg}^{-1}$ 。 与围封相比, 自由放牧使大针茅草原 $0 \sim 5 \mathrm{~cm}$ 表层 和 $5 \sim 15 \mathrm{~cm}$ 下层土壤微生物量碳分别下降了 $38.2 \%$ 和 $12.2 \%$,下降的幅度远远大于土壤有机碳 $(27.3 \%)$ 。土壤微生物量碳的季节变化幅度明显小 于羊草草原, 放牧没有改变它的季节变化形式 (图 2)。围封和自由放牧都是在 8 月下旬植物成熟期达 到高峰, 出现高峰的时间较羊草草原略晚一些。微 生物量碳与地上生物量的变化趋势一致, 对二者的 相关性分析表明, 围封后表层土壤微生物量碳与同 期地上生物量呈显著正相关 $(p<0.05)$, 下层呈极显 著正相关 $(p<0.000)$ 。放牧使得两个层次 4 个取样 时期的土壤微生物量碳都下降, 其中表层土壤各个 时期均达到了显著水平 $(p<0.05)$, 下层土壤放牧后 各个时期无显著性差异。

\subsection{3 冷蒿-小禾草草原微生物量碳}

冷蒿-小禾草草原 $0 \sim 10 \mathrm{~cm}$ 表层土壤平均微生 物量碳为 $347.87 \mathrm{mg} \cdot \mathrm{kg}^{-1}, 10 \sim 20 \mathrm{~cm}$ 下层土壤平均 为 $189.21 \mathrm{mg} \cdot \mathrm{kg}^{-1}$ 。不同放牧强度下土壤微生物量 碳基本接近, 重牧处理中也未见降低 (表 1)。Holt (1997)认为, 用 MB-C/全 $\mathrm{C}$ 的比值能更好地表示放 
牧对微生物量碳库的影响, 放牧使该比值降低。本 实验的测定结果很好地服从了这一规律, 放牧使得 $\mathrm{MB}-\mathrm{C} /$ 全 $\mathrm{C}$ 比值降低, 虽然未达到显著性差异, 但总 体趋势表现为随放牧率的增加 $\mathrm{MB}-\mathrm{C} /$ 全 $\mathrm{C}$ 比值降 低。

\section{2 放牧对易分解碳的影响}

用高锰酸钾氧化法测得的土壤易分解碳较全碳 更敏感地指示土壤环境及性质的变化 (Lefory et al., 1993; Blair \& Lefory, 1995; Moondy et al ., 1987)。由于 土壤易分解碳的碳库容量要大于土壤微生物量碳, 而且受外界环境如土壤温度、湿度的影响较小 (Blair \& Lefory, 1995)。

\subsection{1 放牧对羊草草原易分解碳的影响}

围封后羊草草原表层土壤易分解碳为 4.49 $\mathrm{g} \bullet \mathrm{kg}^{-1}$; 放牧条件下易分解碳为 $3.5 \mathrm{~g} \bullet \mathrm{kg}^{-1}$ 。自由 放牧 22 年后使得表层土壤易分解碳下降了 $22.0 \%$; 下层土壤易分解碳下降了 $12.6 \%$ 。围封后土壤易 分解碳的季节变化比较平缓, 而放牧条件下变化幅 度相对较大, 两个土壤深度都在 $7 \sim 8$ 月达到高峰。 整个生长季节内, 两个土壤深度自由放牧均显著低 于栏内对照, 其中表层在 5 月 12 日和 8 月 19 日达
到极显著水平 $(p<0.01)$, 下层在 5 月 12 日和 9 月 27 日达到显著水平 $(p<0.05)$ (图 3)。土壤易分解 碳的剖面分布也是随土壤深度呈下降的分布规律, 下降的幅度也大于土壤有机碳, 放牧降低了易分解 碳的下降幅度。

羊草草原 $0 \sim 10 \mathrm{~cm}$ 表层土壤不同形态碳素对 放牧影响的反馈指示上: 微生物量碳 > 易分解碳 > 总有机碳, 这说明土壤活性有机碳表征土壤的动态 变化要比土壤总有机碳更加灵敏和直接(图 4)。

\subsection{2 放牧对冷蒿-小禾草草原土壤易氧化碳的影} 响

小禾草草原土壤易氧化碳的季节之间差异不显 著, 易氧化碳与总有机碳和微生物量碳存在很好的 相关性。其中, 易氧化碳与微生物量碳呈显著正相 关 $(p<0.05)$; 易氧化碳与总有机碳也存在一定的正 相关关系。表层土壤平均易氧化碳为 2.59 $\mathrm{mg} \bullet \mathrm{kg}^{-1}$, 下层土壤平均易氧化碳为 $1.20 \mathrm{mg} \bullet \mathrm{kg}^{-1}$ 。 各放牧处理中易氧化碳无显著性差异, 上层土壤中 三种放牧率下无差异, 下层土壤中轻牧略高于中牧 和重牧(表 2)。

放牧也同样使得 Lab-C/全 C 的值降低, 同 MB-

表 2 不同类型草原土壤易分解碳含量 $\left(\mathrm{g} \cdot \mathrm{kg}^{-1}\right)$ 及其剖面分布

Table 2 Impacts of grazing on soil labile carbon and its vertical distribution

\begin{tabular}{|c|c|c|c|c|c|}
\hline \multirow{2}{*}{$\begin{array}{c}\text { 土层 } \\
\text { Soil layer }\end{array}$} & \multicolumn{2}{|c|}{ 羊草草原 Leymus chinensis grassalnd } & \multicolumn{3}{|c|}{ 冷蒿-小禾草草原 Artemisia frigida-short bunchgrasses steppe } \\
\hline & 围封 Enclosure & 自由放牧 Grazing & 轻牧 LG & 中牧 MG & 重牧 HG \\
\hline 表层 Top layer $0 \sim 10 \mathrm{~cm}$ & $4.49 \pm 0.29$ & $3.50 \pm 0.62$ & $2.93 \pm 0.66$ & $2.65 \pm 0.13$ & $2.71 \pm 0.08$ \\
\hline 下层 Sub layer 10 $20 \mathrm{~cm}$ & $2.61 \pm 0.57$ & $2.28 \pm 0.52$ & $1.46 \pm 1.26$ & $1.21 \pm 0.37$ & $1.12 \pm 0.25$ \\
\hline$(\mathrm{T}-\mathrm{S}) / \mathrm{T}(\%)$ & 41.8 & 34.9 & 50.2 & 54.3 & 58.7 \\
\hline
\end{tabular}

1）2): 同表 1 See Table 1

3) $(\mathrm{T}-\mathrm{S}) / \mathrm{T}(\%)$ 为沿土层下降的土壤易分解碳占表层土壤易分解碳含量的百分比 $(\mathrm{T}-\mathrm{S}) / \mathrm{T}(\%)$ is the decrease percent of soil microbial biomass along soil layer to the soil microbial biomass in top soil

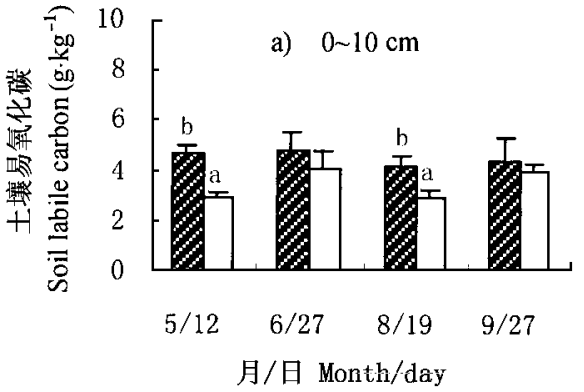

放牧 Grazing

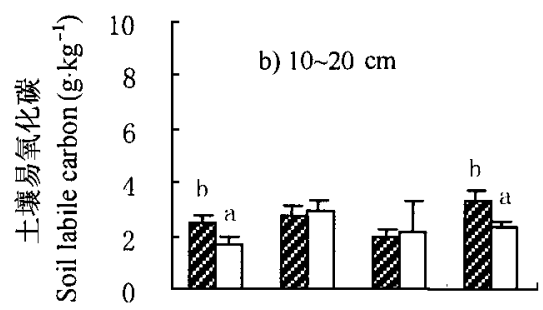

$5 / 12 \quad 6 . / 27 \quad 8 / 19 \quad 9 / 27$

月/日 Month/day

$\%$ 死牧 No grazing 


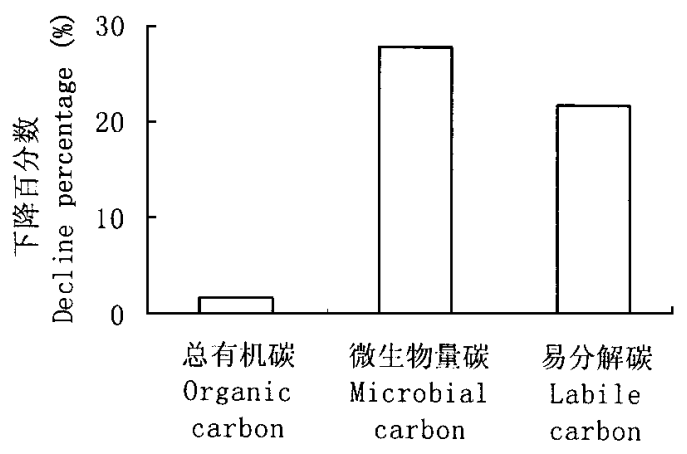

图 4 羊草草原自由放牧 22 年后 $0 \sim 10 \mathrm{~cm}$ 土壤各种 形态碳素下降的百分比

Fig.4 Decline percentage of carbon content after 22 years grazing $\mathrm{C} /$ 全 $\mathrm{C}$ 一样, 在表层和下层土壤中, 所有放牧处理 的 Lab-C/全 C 值随放牧率的增大而递减, 这说明在 放牧对土壤的影响指示上, Lab-C/全 $\mathrm{C}$ 和 $\mathrm{MB}-\mathrm{C} /$ 全 C 要比 MB-C 和 Lab-C 更加敏感。

\section{5 讨 论}

土壤有机碳水平取决于地上凋落物的分解、根 系的周转以及动物排泄物的碳输入和通过土壤呼吸 的碳输出 (Cui et al., 2005), 在一定时期内是处于 特定生态系统下的平衡值。土壤活性有机碳是土壤 中活性较高, 周转速率快, 易于被微生物利用的那部 分碳。已有研究结果表明, 各种方法测得的土壤活 性有机碳都较土壤有机碳更敏感于环境的变化 (Wolters \& Joregensen, 1993; Holt, 1997)。长期连续 免耕及连年施用有机肥和化肥配合, 能显著提高 0 $\sim 5 \mathrm{~cm}$ 土壤微生物量碳和氮( 徐阳春和沈其荣, 2002)。混合草原中度放牧后, 有机碳含量没有明显 的变化, 但其活性碳部分却显著地降低 (Holt, 1997)。 因此, 在研究放牧对土壤碳的影响时, 不仅要考虑到 对总碳库的影响, 还要考虑对土壤各碳素组分的影 响。

1) 本实验中土壤的 3 个指标所代表的碳库容 量, 总有机碳 > 易氧化碳 > 微生物量碳。 Lab-C/OrgC 的比值一般在 $15 \% \sim 25 \%$, 不同生态系统中有所 不同 (Blair \& Lefroy, 1995), 本实验锡林河流域草原 生态系统变化在 17\% 20\% ; 而 $C_{\mathrm{mic}} / C_{\mathrm{org}}$ 的比值一 般为 $1 \% \sim 5 \%$, 本实验中基本变化在 $1.0 \% \sim$ $2.5 \%$ 。土壤微生物量碳库容量虽然小, 但它是比较 活跃的, 较易受到外界环境的干扰, 所以表现为较大 的季节变化幅度。土壤湿度能显著影响土壤微生物 量碳的大小 ( Sparling \& West, 1989); 而总碳和易氧
化碳的季节变化相对较为平缓。

2) 在本实验中的 3 个样地, 土壤总有机碳、微 生物量碳、易氧化碳都表现为表层明显高于下层, 这 是由于土壤有机质主要来源于地上调落物, 并向下 移动。表层土壤微生物活动较下层活跃, 受地表植 物残体归还量影响较大。微生物量碳和易氧化碳沿 土壤剖面下降的幅度都大于总有机碳, 这可能与降 解系数不同的土壤有机碳在剖面中的分布规律不同 有关 (王淑平等, 2003)。Elzein 和 Balesdent (1995) 研 究表明, 降解得比较快的有机碳在土壤中随深度呈 指数下降; 而比较稳定的有机碳在剖面中则均匀分 布。放牧条件下, 碳素沿土壤剖面下降的幅度小于 栏内围封, 这是因为放牧后, 由于牲畜的采食, 地上 生物量包括立枯和调落物量减少, 进入土壤的植物 残体就少。而下层土壤受地表植被状况影响较小, 围封后对其影响要小于表层土壤, 所以下面在研究 放牧对土壤的影响时只考虑对表层土壤的影响。

3 ) 羊草草原和针茅草原自由放牧 22 年后, 与 围封相比, 有机碳含量没有明显降低。这一结论与 该样地以前的实验结果相一致(王艳芬等, 1998; Cui et al.,2005)。放牧后植被的补偿性以及超补偿性 生长, 使得更多的同化碳素向地下转移; 同时由于放 牧造成土壤板结、容重增加等土壤物理性质的改变, 微生物活动减弱, 土壤呼吸降低, 通过呼吸损失的碳 素就减少(崔骁勇等, 2005)。总之土壤自身的缓冲 性能, 使得在一定时期的适牧后, 有机碳库会维持在 一个相对稳定的水平, 不会发生大的变化。但在半 干旱草原由于重度放牧会造成不可恢复的土壤有机 碳库的下降 (Cui et al.,2005)。

4）自由放牧 22 年后, 羊草草原 $0 \sim 10 \mathrm{~cm}$ 表层 易分解碳、微生物量碳分别下降了 $22.0 \%$ 和 $27.9 \%$, 羊草草原微生物量碳的季节变化以及季节与土壤深 度的交互效应都达到了显著水平 $(p<0.05)$ 。微生 物量碳和易氧化碳之间存在明显的正相关; 对大针 茅草原而言, 自由放牧 22 年后, $0 \sim 5 \mathrm{~cm}$ 表层土壤微 生物量碳下降了 $38.2 \%$ 。这说明在羊草和针茅草 原, 由放牧导致土壤碳素的损失是比较明显的, 而且 土壤微生物量碳和易氧化碳比土壤碳总储量更好地 反映出家畜放牧影响下土壤有机碳的早期变化 (Holt, 1997)。

冷蒿-小禾草草原连续实验放牧 8 年后, 不同放 牧率下土壤有机碳含量没有显著性差异。甚至重牧 条件下有机碳有偏高的趋势。但李香真和陈佐忠 (1998) 曾观测到, 对照 $0 \sim 10 \mathrm{~cm}$ 表层土壤有机碳含 
量显著高于各放牧处理，而放牧处理间差异不显著。 一般认为, 放牧使土壤微生物量碳降低(Holt, 1997)。 但我们发现冷蒿-小禾草草原在不同放牧率下土壤 微生物量碳和易氧化碳都没有显著性差异, 重牧处 理中也没有降低。Holt (1997)认为, 用 MB-C/全 C 的 比率能更好地表征放牧对微生物量碳库的影响, 放 牧使该比值降低。本实验的测定结果很好地服从了 这一规律, 随放牧率的增加, MB-C/全 C 比值和 Lab$\mathrm{C} /$ 全 $\mathrm{C}$ 比值逐渐降低, 表现为轻牧 > 中牧 > 重牧, 这说明, 在表征放牧对冷蒿-小禾草草原土壤的影响 指示上, Lab-C/全 C 和 MB-C/全 C 要比 MB-C 和 LabC 敏感。

5) 放牧是草地生态系统最主要的利用方式, 对 草原土壤系统的影响较植物滞后, 与放牧率、放牧时 间以及气候、植物种类组成等多种因素有关, 是一种 间接的影响 (李香真和陈佐忠, 1998)。本实验中, 3 种草原对放牧的不同响应, 笔者认为除了与土壤以 及植物有关外，放牧持续的时间和放牧压力的不同 可能也是一个重要的原因。羊草样地和大针茅样地 围封时间为 22 年, 放牧样地试验时间为 11 年恢复 2 年, 土壤自身的缓冲性能可能使得土壤总有机碳对 放牧的响应在短时期内不明显(王艳芬等, 1998)。

\section{参 考 文 献}

Blair BJ, Lefroy RD(1995) . Soil carbon fractions based on their degree of oxidation, and the developments of a carbon management index for agriculture systems. Australian Journal of Agriculture Research, 46, 1456 - 1466.

Bauer JD, Armand CV, Black AL(1987) . Soil property comparisons in virgin grasslands between grazed land non-grazed management systems. Soil Science Society of America Journal, 51, 176 - 182.

Biederbeck BO, Zentner RP(1994). Labile soil organic matter as influenced by cropping practices in an arid environment. Soil Boilogy and Biochemistry, 26,1647 - 1656.

Cui XY, Wang YF, Niu HS, Wang SP, Schnag E, Rogasik J, Flecenstein J, Tang YH (2005). Effect of long-term grazing on soil organic carbon content in semiarid steppe in Inner Mongolia. Ecological Research, 20, DOI: 10.1007/S 11284-005-0063-8

Derner JD, Beriske DD, Boutton TW (1997). Dose grazing mediate soil carbon and accumulation beneath $\mathrm{C}_{4}$, perennial grasses along an environmental gradient? Journal of Range Management, 24, $308-309$.

Elzein A, Balesdent J(1995) . A mechanistic simulation of the vertical distribution of carbon concentrations and residence time in soil. Soil Science Society of America Journal, 59,1328 - 1335.

Frank AB, Tanaka DL, Hofmann L, Follett RF(1995). Soil carbon and nitrogen of Northern Great Plains grasslands as influenced by long-term grazing. Journal of Range Management, 48,470 - 474. Graetz D (1994). Grasslands. In: Meyer BL, Turner WB eds. Changes in Land-Use and Land-Cover: a Global Perspective. Cambridge University Press, Cambridge UK, 125.

Holt JA (1997) . Grazing pressure and soil carbon, microbial biomass and enzyme activities in semi-arid northeastern Australia. Journal of Applied Soil Ecology, 5,143 - 149.

Houghton RA (1995). Changes in the storage of terrestrial carbon since 1850. In: Lai R ed. Soils and Global Change. CRC Press, Inc, Roca Raton, Florida, 45 - 65 .

IPCC (2001). The Third Evaluation Report: Climate Change, Synthesis Report. Cambridge University Press, Cambridge. 8-10.

Jenkinson DS , Powlson DS (1976). The effects of biocidal treatments on metabolism in soil - a method for measuring soil biomass. Soil Biology and Biochemistry, 8, 189-202.

Jenkinson DS, Odes JM (1979) . A method for measuring adenosine in soil. Soil Biology and Biochemistry, 11, $193-199$.

Keeling CD(1997) . Climate change and carbon dioxide. An introduction National Academy of Science, 94,8273 - 8274.

Li XZ(李香真), Chen ZZ(陈佐忠) (1998). Impacts of plant and soil C, N, P contents on different stocking rate. Acta Agrestia Sinica (草地学报) , 16,90-98. (in Chinese with English abstract)

Li LH(李凌浩) (1998). Effects of land-use change on soil carbon storage in grassland ecosystems. Acta Phytoecologica Sinica (植 物生态学报),22,300-302. (in Chinese with English abstract) Lin QM(林启美), Wu YG( 吴玉光) (1999). Modification of fumigation extraction method for measuring soil microbial biomass carbon. Chinese Journal of Ecology (生态学杂志), 18(2), 63 - 66. (in Chinese with English abstract)

Lefory RDB, Blair GJ, Strong WM (1993). Changes in soil organic matter with cropping as measured by organic carbon and ${ }^{13} \mathrm{C}$ natural isotope abundance. Plant and Soil, 155-156,399-402 .

Mazzarino MJ, Szott L, Jimenez M (1993). Dynamics of soil total $\mathrm{C}$ and $\mathrm{N}$, microbial biomass, and water-soluble $\mathrm{C}$ in tropical agroecosystems. Soil Biology and Biochemistry, 25,205- 214.

Marumoto TJ, Domsch KH(1982). Mineration of nutrients from soil microbial biomass. Soil Biology and Biochemistry, 14,469- 475.

Moondy HA, Vitousek PM, Matson PA(1987). Exchange of material between terrestrial ecosystem and the atmosphere. Science, 238, $926-932$.

Milchunas DG, Lauenroth WK(1993) . Quantitative effects of grazing on vegetation and soil over a global range of environments. Ecological Monographs, 63,327-366.

Sampson RN, Apps M, Brown S(1993). Terrestrial biosphere carbon fluxes quantification of sinks and sources of $\mathrm{CO}_{2}$. Water Air and Soil Pollution, 70,3-15.

Sparling GP, West AW (1989). Importance of soil water content when estimating soil microbial $\mathrm{C} 、 \mathrm{~N}$ and $\mathrm{P}$ by the fumigation-extraction methods. Soil Biology \& Biochemistry, 21,245-253.

Schuman GE, Reeder JD, Manley JT, Hart RH, Manley WA 
(1999). Impact of grazing management on the carbon and nitrogen balance of a mixed-grass rangeland. Ecological Applications, $9,65-71$.

Wang YF(王艳芬), Chen ZZ(陈佐忠), Tieszen LT(1998). Distribution of soil organic carbon in the major grasslands of Xilingole, Inner Mongolia, China. Acta Phytoecologica Sinica (植物 生态学报),22,545-551. (in Chinese with English abstract)

Wang SP(王淑平), Zhou GS(周广胜), Gao SH(高素华), Guo JP (郭建平) (2003). Distribution of soil labile carbon along the Northeast transect (NECT) and its response to climate change. Acta Phytoecologica Sinica (植物生态学报), 27,780-785. (in Chinese with English abstract)
Watson RT, Verardo DJ(2000). Land-Use Change and Forestry. Cambridge University Press, Cambridge.

Weinhold BJ, Henndrickson JR, Karn JF (2001) . Pasture management influences on soil properties in the Northern Grain plains. Journal of Soil and Water Conservation, 56, 27 - 31 .

Wolters V, Joergensen RG(1993). Microbial biomass and its contribution to nutrient concentrations in forest soils. Soil Biology and Biochemistry, 25, $25-31$.

XU YC(徐阳春)，Shen QR (沈其荣) (2002). Impacts on soil microbial C, N, P under long-term no-till and organic manure spreading. Acta Pedologica Sinica (土壤学报), 39, 89-95. (in Chinese with English abstract)

责任编委：欧阳 华 责任编辑: 张丽赫 